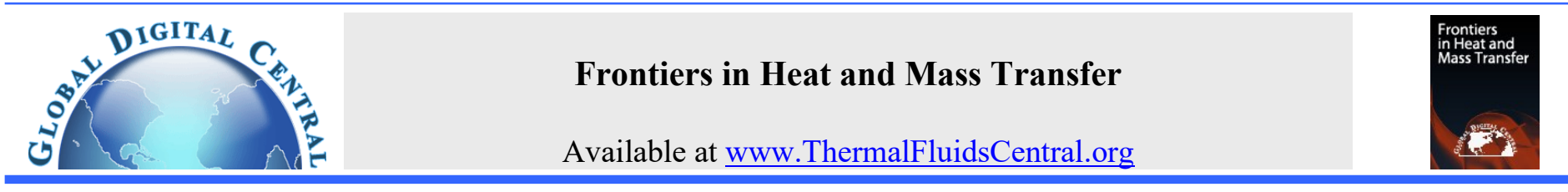

\title{
EFFICIENCY CENTERED MAINTENANCE FOR PREHEAT TRAINS OF CRUDE OIL DISTILLATION UNITS
}

\author{
Daniel Yabrudy Mercado a, ${ }^{\mathrm{a}}$, Juan Fajardo Cuadro ${ }^{\mathrm{a}}$, Bienvenido Sarria López ${ }^{\mathrm{b}}$, Camilo Cardona Agudelo ${ }^{\mathrm{b}}$ \\ ${ }^{a}$ Mechanical Engineering Program, Universidad Tecnológica de Bolivar, Cartagena, Bolívar, Colombia \\ ${ }^{b}$ Maintenance Management, Ecopetrol - Reficar S.A., Cartagena, Bolivar, Colombia
}

\begin{abstract}
This paper presents the efficiency-centered maintenance method to plan the maintenance intervention of the heat exchangers of a preheat train, taking into account the economic-energy improvement and maintenance cost. An appropriate cleaning schedule is needed to preserve the key performance parameters (KPPs) throughout the operation, if possible, nearest to the design values. The results of this work show that it is possible to schedule maintenance activities based on KPPs such as effectiveness and determine the time of execution and the type of maintenance that is most cost-efficient, without affecting and complementing the criteria for maintenance schedules based on reliability/risk.
\end{abstract}

Keywords: cleaning schedule, preheat trains, crude oil, crude distillation unit, refineries.

\section{INTRODUCTION}

Heat exchangers (HE) are equipment used to heating/cooling one fluid, taking advantage of the high or low temperature of another. In a crude distillation unit, these $\mathrm{HE}$ are used to reuse the temperature (thermal energy) acquired by the products coming from the distillation tower, after being subjected to heating in an oven where fuel (mostly natural gas) is burned (Cengel, 2003; Incropera et al., 2011; Kuppan, 2013; Schlunder, 1983; Shah and Sekulić, 2003).

Fouling is the phenomenon that most affects heat exchangers. Bott (1995) defines fouling as unwanted accumulations of sediment on the surfaces where heat exchange occurs, which increases resistance to heat transfer and decreases the efficiency of the exchanger. It also clarifies that said fouling can be due to organic, inorganic materials, and even the result of chemical reactions.

Namely, fouling degrades the ability to exchange heat, leading to insufficient equipment performance (Caputo et al., 2011; Ishiyama et al., 2008; Rodriguez and Smith, 2007; Smaili et al., 2001; Zubair et al., 2000). Maintenance interventions are necessary to restore the initial performance/efficiency of the equipment (Georgiadis and Papageorgiou, 2000; Georgiadis et al., 2000; Rodriguez and Smith, 2007; Zubair et al., 2000). This fouling phenomenon costs billions of dollars a year to refineries around the world (Bennett, 2012; Borges et al., 2009; Bott, 1995; Coletti and Francesco, 2010; Coletti and Macchietto, 2009; de Oliveira Filho et al., 2009; Ishiyama et al., 2008; Waters et al., 2009; Yeap et al., 2004); since it brings with it higher consumption of natural gas in the oven, to achieve the necessary temperature for the distillation process in addition to the unwanted environmental effects. Furthermore, the changes in the diet (the composition of the Crude oil that enters the unit) monthly, weekly, or daily, according to the company's refining objectives and the desired profit margins. They accelerate the loss of equipment efficiency and the growth of fouling.

Up to now, maintenance planning in heat exchanger networks (fouling cleaning program) has been addressed as an optimization problem, and the proposed solutions that have been presented were found through linear and non-linear programming algorithms.

Georgiadis and Papageorgiou (2000) developed a MILP model (mixed-integer linear programming) that determined the number of cleaning interventions, confirming that the performance of a heat exchanger decreases over time. Therefore, it is necessary to program a service shutdown to clean the equipment and recover its performance. But these mathematical models are not generated from real data of temperatures and mass flows of the process that allow adjusting them after each intervention to determine with greater precision the optimal moments of the following interventions.

Zubair et al. (2000) performed a thermal and economic analysis on heat exchangers in which fouling exists. Initially, they carried out a characterization of the fouling models found in the industry. Later they investigate the effect of fouling on performance, overall heat transfer coefficient, and outlet temperatures. They also presented a maintenance strategy based on costs, looking for the solution based on the minimum cost, showing that the optimal cost is very close to the moment where the level of fouling is critical.

Smaili et al. (2001) developed their method by placing all cleaning interventions at the same distance and then searching for the best local optimum through non-linear programming (MINLP). They observed that some exchangers affect the overall performance of the system. They called them Key Heat Exchangers, but the cost-benefit relationships of these interventions are not analyzed.

Sepehr Sanaye and Behzad Niroomand (2007) show a simulation of a HEN and the planning of the optimal cleaning program, using the asymptotic fouling model. They predict the outlet temperature of each stream in two HENs and optimize the cleaning schedule based on cost/savings. Borges et al. (2009) and De Oliveira et al. (2009) propose to treat fouling by optimizing the division of flow. His case study was a real refinery and shows that optimizing hot and cold streams has a significant impact on cost. Izyan et al. (2014) present two models for cleaning programming as for HEN adaptation using a non-linear mixedinteger programming model (MINLP). In their second model, they 
manage to minimize the cost of energy and cleaning, a higher overall heat transfer coefficient, and lower fouling rates than conventional heat exchangers. Biyanto et al. (2016) They seek the planning of an optimal cleaning program, through non-linear programming MINLP and Stochastic Optimization Methods. In their results, they showed that the optimal solution without simplifications, that is, taking into account the additional cost of pumping allows more significant savings to be achieved. However, the authors do not take into account different types of maintenance or the costs of lost earnings corresponding to each of them, as if they are taken into account in this work.

This paper proposes planning of the cleaning schedule for a network of heat exchangers in a crude oil unit, through energy-economic indicators. Initially, the degradation of the key performance parameters (KPPs) and its effect on the economic-energy indicators are diagnosed. Then, the indicators of maintenance focused on energy efficiency $(\varepsilon, J)$ are calculated, to subsequently carry out the planning of the cleaning that is economically justified. The authors propose a simple methodology, based on the literature found, in addition to an economic indicator called $\mathrm{J}$, for an economic-energy justification for maintenance interventions and determine the time of execution and the type of maintenance that is most cost-efficient, without affecting and complementing the criteria for maintenance schedules based on reliability and risk.

\section{METHODOLOGY}

Figure 1 schematically represents the implemented methodology. Based on the exploration and analysis of the scientific literature, the following are presented: 1) Models for calculating the properties of crude oil (density, viscosity and specific heat at constant pressure). 2) The equations necessary for the calculation of the energy performance parameters that allow the diagnosis of the CDU exchangers under study. That is, the thermal resistance of the fouling $\left(R_{f}\right)$, the global heat transfer coefficient (U), the thermal resistance (Q), the effectiveness ( $(\varepsilon)$. 3) The indicator J proposed by the authors. 4) Criticality analysis, e) Models to predict the performance of exchangers and, 5) Maintenance planning.

\subsection{Description of the process unit}

The crude oil refining process begins with the Crude Distillation Unit (CDU), its capacity is $994 \mathrm{~m}^{3} / \mathrm{h}(150,000 \mathrm{BPD})$ of crude oil in intermediate products, which are later processed in other units within the refinery, to improve its properties. The crude mixture from the raw materials unit enters the CDU, at an average temperature of $32^{\circ} \mathrm{C}$. This mixture first passes through the network of heat exchangers (called preheating train), object of study, and then enters the atmospheric furnace where its temperature rises to $371^{\circ} \mathrm{C}$. The process continues in the distillation column where the derivatives are separated.

The preheating train is made up of a network of tube and shell heat exchangers, configured in series / parallel, where a regeneration process takes place.

The preheating train takes advantage of the thermal energy that must be extracted from the products that leave the distillation column at high temperature, transferring it to the crude through each exchanger in the network without mixtures between them (Cengel, 2003; Incropera et al., 2011; Kuppan, 2013; Schlunder, 1983; Shah and Sekulić, 2003), thus reducing the amount of natural gas or refinery gases that must be burned, and therefore the emissions of polluting gases to the environment. (Assis et al., 2013; Ishiyama et al., 2010; Waters et al., 2009; Yeap et al., 2004).

Figure 2 shows the diagram of the preheating train analyzed. The crude represents it the red lines represent the; and the blue lines are the streams that leave the distillation column and transfer heat to the crude: 1) heavy vacuum fuel oil (HVGO), 2) medium vacuum fuel oil (MVGO), 3) atmospheric fuel oil (AGO ), 4) Heavy Diesel (HDIESEL), and, 5) Residues of pitch or vacuum (VR).

\subsection{Crude oil properties models}

Taking into account that the properties of crude oil change with temperature, Mathematical models of these properties as a function of temperature must be available to determine them accurately. As the mathematical models proposed by Polley et al. (2002) that have been used by Tian et al., 2016 and Tajudin (2015), In this work the models developed by Tajudin will be used because they have a better correlation Then, the Tajudin model (equation 1) is used for the density and Polley's Equation (equation 2) for specific heat, where $\mathrm{T}$ is the temperature in degrees Celsius in both. Table 1 presents the standard thermodynamic properties of each of the process streams, numbered in Fig. 2.

$$
\begin{aligned}
& \rho=(-0.6578 T+896.84) \times 0.0624279606 \\
& C_{p}=(3 T+1940) \times 0.00023884589663
\end{aligned}
$$

\section{KEY PERFORMANCE PARAMETERS}

The conception of the behavior of a heat exchanger is an important approach to develop the thermal performance of the heat exchanger (Boonloi and Jedsadaratanachai, 2019). It is also important to understand the process to achieve production goals and energy use reduction ( $\mathrm{Ba}$ et $a l, 2019)$. All of the above can be called device/system diagnostics. For developing a diagnostic model of a heat exchanger network, it is necessary to study the behavior of the key performance parameters KPPs in each heat exchanger. It consists of the evaluation in time of the global heat transfer coefficient (U), the heat output $(\mathrm{Q})$, and the efficiency $(\varepsilon)$. The diagnosis is based on the real data collected in a crude distillation unit, in approximately 30 months.

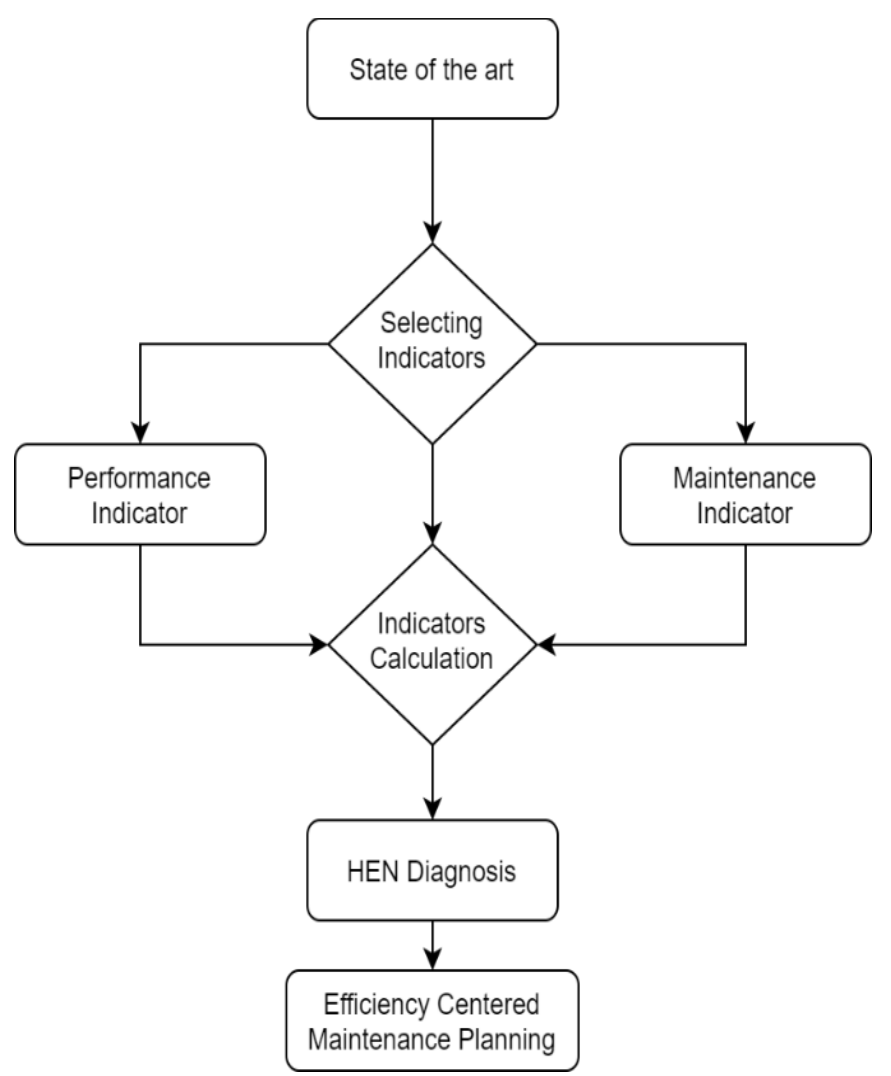

Fig. 1 Outline of the research methodology. 




Fig. 2 Scheme of the preheating train of a crude distillation unit.

Table 1 Temperatures and mass flow of process streams

\begin{tabular}{|c|c|c|c|}
\hline State & Substance & Temperature $\left({ }^{\circ} \mathrm{C}\right)$ & Mass flow $(\mathrm{kg} / \mathrm{hr})$ \\
\hline 0 & CRUDE & 167 & 906,276 \\
\hline 1 & CRUDE & 167 & 453,138 \\
\hline 2 & CRUDE & 180 & 453,138 \\
\hline 3 & CRUDE & 196 & 453,138 \\
\hline 4 & CRUDE & 215 & 453,138 \\
\hline 5 & CRUDE & 224 & 453,138 \\
\hline 6 & CRUDE & 236 & 453,138 \\
\hline 7 & CRUDE & 236 & 226,569 \\
\hline 8 & CRUDE & 247 & 226,569 \\
\hline 9 & CRUDE & 268 & 258,752 \\
\hline 10 & CRUDE & 292 & 258,752 \\
\hline 11 & CRUDE & 316 & 258,752 \\
\hline 12 & CRUDE & 236 & 226,569 \\
\hline 13 & CRUDE & 249 & 226,569 \\
\hline 14 & CRUDE & 266 & 226,569 \\
\hline 15 & CRUDE & 287 & 226,569 \\
\hline 16 & CRUDE & 314 & 226,569 \\
\hline 17 & MVGO & 261 & 320,916 \\
\hline 18 & MVGO & 245 & 320,916 \\
\hline 19 & MVGO & 232 & 320,916 \\
\hline 20 & MVGO & 210 & 320,916 \\
\hline 21 & MVGO & 193 & 320,916 \\
\hline 22 & HDIESEL & 293 & 114,214 \\
\hline 23 & HDIESEL & 224 & 114,214 \\
\hline 24 & AGO & 332 & 118,841 \\
\hline 25 & AGO & 293 & 118,841 \\
\hline 26 & HVGO & 348 & 259,227 \\
\hline
\end{tabular}

\begin{tabular}{|l|l|l|l|}
\hline 27 & HVGO & 332 & 259,227 \\
\hline 28 & HVGO & 297 & 259,227 \\
\hline 29 & HVGO & 274 & 259,227 \\
\hline 30 & VR & 361 & 165,924 \\
\hline 31 & VR & 324 & 165,924 \\
\hline 32 & VR & 296 & 165,924 \\
\hline 33 & VR & 273 & 165,924 \\
\hline 34 & VR & 254 & 165,924 \\
\hline
\end{tabular}

\subsection{Fouling resistance}

It is the resistance to heat transfer provided by the fouling layer, formed over time, and due to the temperature conditions and properties of the crude oil. Wang et al. (2017) studied fouling behavior through numerical methods, showing an asymptotic fouling resistance model. The fouling behavior of the heat exchangers in the study fits the Kern y Seaton correlation (asymptotic model) (Caputo et al., 2011; D. Kern and Seaton, 1959; Ludwig, 1997; Sanaye and Niroomand, 2007; Schlunder, 1983; Yeap et al., 2004), presented in eq. (3). This correlation allows only with time and an asymptotic value, the diagnosis, and prediction of fouling in a heat exchanger.

$$
R_{f}(t)=R_{f}^{*}\left(1-e^{-t / \tau}\right)
$$

Where $R_{f}^{*}$ is the asymptotic fouling resistance, which depends on the speed, diameter, type of fluid, among others. This value can be taken from the TEMA Standards (Tubular Exchanger Manufacturers Association Inc., 2007), or empirically adjusted by adjusting the exchanger data (Sanaye and Niroomand, 2007). $\tau$, called decay time, must be empirically calculated, taking into account the behavior of each exchanger. Finally, $t$ is the time elapsed since the last maintenance in days.

\subsection{Fitting the asymptotic fouling resistance and decay time values}

For fitting of these values, the experimental overall heat transfer coefficient is computed with eq. (4). The empirical data of mass flow, 
and inlet and outlet temperatures were obtained from historical dataloggers for each heat exchanger in the HEN for about 30 months approximately. Heat transfer area $(A)$ and design overall heat transfer coefficients $\left(U_{d}\right)$ were found in technical datasheets.

$U_{\mathrm{e}}=\frac{\dot{m} C_{\mathrm{p}} \Delta T}{A \Delta T_{l m}}$

Then an experimental $R_{f_{-} e}$ is calculated using the eq. (5):

$R_{f_{-} \mathrm{e}}=\frac{1}{U_{\mathrm{e}}}-\frac{1}{U_{d}}$

The value of asymptotic fouling resistance $\left(R_{f}^{*}\right)$ is computed by eq. (6). In order to estimate $\tau$, values of eq. (3), with the $R_{f}^{*}$ computed and $\tau=\mathrm{t}$, are compared with values of eq. (5). The $\tau$ is adjusted looking for the best match. Metrics RMSE and R2 are used to check the best fit.

$$
R_{f}^{*}=\frac{1}{n} \sum R_{f_{-} \exp }
$$

\subsection{Overall heat transfer coefficient}

It can be defined as the set of all the resistances involved in the heat transfer process. To calculate the $U$ of the equipment in fouled conditions, we proceed with eq. (7), according to the literature found (Biyanto et al., 2016; Sanaye and Niroomand, 2007; Watkinson, 2003).

$$
U_{f}(t)=\frac{1}{\frac{1}{U_{d}}+R_{f}(t)}
$$

Where $U_{f}(t)$ is the global coefficient of heat transfer under fouled conditions, $U_{d}$ is the design overall heat transfer coefficient, and $R_{f}(t)$ is the fouling resistance computed with eq.(3).

\subsection{Heat Duty}

For calculating the current heat flow or heat duty, eq. (8) is used (Cengel, 2003; Incropera et al., 2011; Kaminski and Jensen, 2005; D. Q. Kern, 1997; Schlunder, 1983; Tubular Exchanger Manufacturers Association Inc., 2007). (Sanaye and Niroomand, 2007) use this Equation in their methodology to perform a simulation of a network of heat exchangers (HEN) and the planning of the optimal cleaning program for it. (Biyanto et al., 2016), apply this Equation in their methodology to plan the cleaning of heat exchangers that belong to a crude oil preheating train. For their part, (Tian et al., 2016) use eq. (8) in their study to develop a simultaneous optimization of the flow rate and a cleaning program to mitigate fouling in the heat exchanger networks of a refinery.

$$
\dot{Q}=U_{f}(t) \times A \times C L M T D
$$

The logarithmic mean temperature (LMTD) relates the four temperatures present in a heat exchanger ( $\mathrm{T}$ cold side inlet, $\mathrm{T}$ cold side outlet, $\mathrm{T}$ hot side inlet, $\mathrm{T}$ hot side outlet). The exchangers under study are counterflow. Equation (9) present the way to calculate it (Biyanto et al., 2016; Kuppan, 2013; Sanaye and Niroomand, 2007; Schlunder, 1983).

$$
\Delta T_{l m}=\frac{\left(T_{h, i}-T_{c, o}\right)-\left(T_{h, o}-T_{c, i}\right)}{\ln \left(\frac{T_{h, i}-T_{c, o}}{T_{h, o}-T_{c, i}}\right)}
$$

it is necessary to use a correction factor for each case, which corrects the LMTD. The correction factor $f$ taken for each case was the one calculated by the designer, recorded in the technical sheets of each device (Biyanto et al., 2016; Cengel, 2003; Kuppan, 2013; Sanaye and Niroomand, 2007; Schlunder, 1983). Equation (10) shows the corrected Logarithmic mean temperature difference.

$$
C L M T D=f \times \Delta T_{l m}
$$

\subsection{Thermal Effectiveness}

Effectiveness is defined as the ratio between the current heat flow and the maximum thermodynamically possible heat flow with the current flow and temperature conditions. (Kuppan, 2013; Shah and Sekulić, 2003) (eq 11). According to Yeap et al. (Yeap et al., 2004), This is the most convenient method for heat exchanger networks.

$\varepsilon=\frac{\dot{Q}}{\dot{Q}_{\max }}$

Where, $\dot{Q}_{\max }$ is the product of the minimum heat capacity $\left(C_{\min }\right)$ with the difference of the highest temperature ( $\mathrm{T}$ inlet on the hot side) and the lowest temperature in the system ( $\mathrm{T}$ inlet on the cold side)(Cengel, 2003; Incropera et al., 2011) (equation 12).

$\dot{Q}_{\max }=C_{\min }\left(T_{h, i}-T_{c, i}\right)$

\subsection{Indicator J}

Indicator $\mathrm{J}$ is defined as the ratio of the cost of energy lost from fouling to the total cost of maintenance activity plus lost profit (Eq. 13). This factor will determine if the maintenance activity is economically viable.

$J=\frac{\sum \Delta \dot{Q} \times C_{e}}{\sum C_{m a \text { int }+l p}}$

where:

$\Delta \dot{Q}=\dot{Q}_{r e f}-\dot{Q}$

The cost of the energy no transferred is equal to de difference between the actual heat duty and the reference heat duty times a unitary cost, which depends on business conditions, among others. In economic terms, what is sought is that the opportunity cost is optimal (an optimal opportunity cost is zero or negative). A decision threshold must be chosen to determine when intervention on the device will be justified.

With a value of $J$ equal to two, performing the maintenance task implies a win-win strategy, since the opportunity cost will be equal to the maintenance cost plus the lost profit.

\subsection{Criticality analysis}

Based on the obtained values of Effectiveness and $\mathrm{J}$, a criticality assessment matrix is proposed in Fig. 3. Similar to a Risk assessment matrix (RAM), the criticality assessment matrix (CAM) is a twodimensional matrix that helps to characterize the criticality of the interventions for each heat exchanger in the net, according to the loss of its performance, represented in the values of Effectiveness and $\mathrm{J}$.

The visual indicators of the matrix, help in identifying the criticality of the interventions. The red color being the most critical condition, which must be intervened promptly, and the green color being a good condition of the device. The intermediate colors light green, yellow, and orange represent intermediate states of the equipment condition, between the best condition (green) and the worst condition (red). 


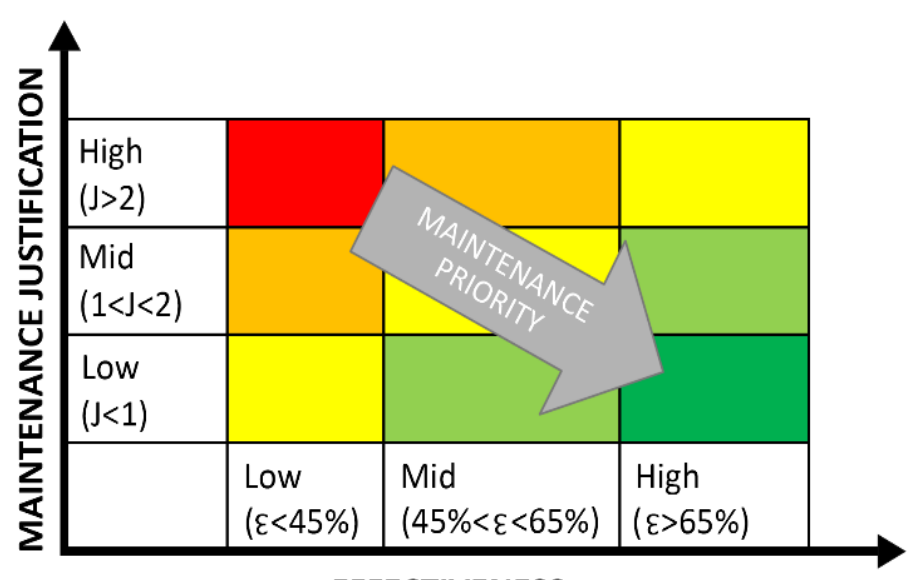

EFFECTIVENESS

Fig. 3 Criticality assessment matrix.

\subsection{Prediction models for Maintenance Planning}

The existing data was fitted through the MATLAB ${ }^{\circledR}$ curve fitting tool (MATLAB R2019b, The MathWorks Inc., version 9.7.0.1296695, USA), which provides regression models using the least-squares method, among others. The metrics used to accept the adjustments were RMSE as primary and SSE (sum of squares of error) as secondary. The RMSE was compared to the standard deviation of the data. Those adjustments where the RMSE was less than or equal to the deviation from existing trends were accepted. Also, it was sought that the SSE be as close as possible to zero. The RMSE allows us to validate the model for the forecast and the SSE the fit of the data to said model. Table 2 shows the models used to fit the data. The adjusted data were heat flow and effectiveness, both versus time.

Table 2 Models for heat flow and performance adjustment.

\begin{tabular}{|l|l|}
\hline Name & Model \\
\hline Power1 & $a t^{b}$ \\
\hline Power2 & $a t^{b}+c$ \\
\hline Exp & $a e^{b t}+c e^{d t}$ \\
\hline Gauss & $a e^{-\left(\frac{t-b}{c}\right)^{2}}+d e^{-\left(\frac{t-f}{g}\right)^{2}}$ \\
\hline
\end{tabular}

\subsection{Maintenance Planning}

Considering the CAM (Fig. 3), the heat flow forecast models, and the effectiveness models, maintenance planning is performed. Table 3 describes the types of maintenance and the values that indicator $\mathrm{J}$ must reach for maintenance to be feasible. Table 4 shows the costs for each type of maintenance

Table 3 Decision thresholds for indicator J

\begin{tabular}{|c|c|}
\hline Indicator $J$ & Type of maintenance and conditions \\
\hline 2 & $\begin{array}{l}\text { Maintenance A: } \\
\text { - } \quad \text { Long plant stops (at least } 15 \text { days). } \\
\text { - } \quad \text { Mechanical cleaning in specialized workshop. } \\
\text { - } \quad \text { Change of tubes or parts if necessary. } \\
\text { - } \quad \text { Transportation of heavy equipment. }\end{array}$ \\
\hline
\end{tabular}

\begin{tabular}{|c|c|}
\hline 2 & $\begin{array}{l}\text { Maintenance B: } \\
\text { - } \quad \text { On-site maintenance. } \\
\text { - } \quad \text { Minor repairs. } \\
\text { - } \quad \text { mechanical cleaning, with water jet, sand, } \\
\text { pressurized air. } \\
\text { - Shorter times, transportation costs, and } \\
\text { logistics. }\end{array}$ \\
\hline 3 & $\begin{array}{l}\text { Maintenance C: } \\
\text { - } \quad \text { Chemical wash } \\
\text { - } \quad \text { No disassembly of equipment is required. } \\
\text { - } \quad \text { Short downtimes } \\
\text { - } \quad \text { L ow transport and logistics costs }\end{array}$ \\
\hline
\end{tabular}

Table 4 Maintenance costs and lost profit

\begin{tabular}{|l|l|}
\hline Maintenance type & Cost/area $\left(\mathrm{USD} / \mathrm{m}^{2}\right)$ \\
\hline Maintenance A: Service shutdown & 80.30 \\
\hline Maintenance B: Onsite Maintenance & 36.50 \\
\hline Maintenance C: Online Maintenance & 14.60 \\
\hline
\end{tabular}

\section{RESULTS}

The results of the application of the methodology described above are presented below. Table 5 and 6 show the general data of the exchangers under study.

Table 5 Heat exchangers data 1

\begin{tabular}{|l|l|l|l|l|}
\hline Component & Fluid shell/tube & $\begin{array}{l}\text { Shell } \\
\text { Temperature } \\
\text { in/out }\left({ }^{\circ} \mathrm{C}\right)\end{array}$ & $\begin{array}{l}\text { Tube } \\
\text { Temperature } \\
\text { in/out }\left({ }^{\circ} \mathrm{C}\right)\end{array}$ & $\begin{array}{l}\text { mass flow } \\
\text { shell/tube } \\
(\mathrm{Kg} / \mathrm{h})\end{array}$ \\
\hline HX-1-1/3 & MVGO/Crude & $232 / 210$ & $180 / 196$ & $\begin{array}{l}320,916 / \\
453,138\end{array}$ \\
\hline HX-1-2/4 & MVGO/Crude & $210 / 193$ & $167 / 180$ & $\begin{array}{l}320,916 / \\
453,138\end{array}$ \\
\hline HX-2-1/2 & HDIESEL/Crude & $293 / 224$ & $196 / 215$ & $\begin{array}{l}114,214 / \\
453,138\end{array}$ \\
\hline HX-3-1/3 & MVGO/Crude & $261 / 245$ & $224 / 236$ & $\begin{array}{l}320,916 / \\
453,138\end{array}$ \\
\hline HX-3-2/4 & MVGO/Crudo & $245 / 232$ & $215 / 224$ & $\begin{array}{l}320,916 / \\
453,138\end{array}$ \\
\hline HX-4 & AGO/Crude & $332 / 293$ & $236 / 247$ & $\begin{array}{l}118,841 / \\
226,569\end{array}$ \\
\hline HX-5-1/2 & HVGO/Crude & $348 / 322$ & $292 / 316$ & $\begin{array}{l}259,227 / \\
258,752\end{array}$ \\
\hline HX-5-3/5 & HVGO/Crude & $322 / 297$ & $268 / 292$ & $\begin{array}{l}259,227 / \\
258,752\end{array}$ \\
\hline HX-5-4/6 & HVGO/Crude & $297 / 274$ & $247 / 268$ & $\begin{array}{l}259,227 / \\
258,752\end{array}$ \\
\hline HX-6-1/3 & VR/Crude & $361 / 324$ & $287 / 314$ & $\begin{array}{l}165,924 / \\
226,569\end{array}$ \\
\hline HX-6-2/4 & VRCrude & $324 / 296$ & $266 / 287$ & $\begin{array}{l}165,924 / \\
226,569\end{array}$ \\
\hline HX-6-5/7 & VRCrude & $296 / 273$ & $249 / 266$ & $\begin{array}{l}165,924 / \\
226,569\end{array}$ \\
\hline HX-6-6/8 & VR/Crude & $273 / 254$ & $236 / 249$ & $\begin{array}{l}165,924 / \\
226,569\end{array}$ \\
\hline
\end{tabular}


Table 6 Heat exchangers data 2

\begin{tabular}{|l|l|l|l|l|}
\hline Component & $\begin{array}{l}\text { design heat } \\
\text { transfer } \\
\text { capacity } \\
\text { (M.W.) }\end{array}$ & $\begin{array}{l}\text { operation } \\
\text { heat transfer } \\
\text { capacity } \\
\text { (M.W.) }\end{array}$ & $\begin{array}{l}\text { Heat } \\
\text { transfer } \\
\text { area }(\mathrm{m} 2)\end{array}$ & $\begin{array}{l}\text { Correction } \\
\text { factor } \\
\text { LMTD }\end{array}$ \\
\hline HX-1-1/3 & 9.64 & 7.12 & 535.05 & 0.9922 \\
\hline HX-1-2/4 & 7.84 & 5.79 & 535.05 & 0.9922 \\
\hline HX-2-1/2 & 11.77 & 10.95 & 403.57 & 0.9916 \\
\hline HX-3-1/3 & 7.28 & 5.36 & 567.51 & 0.9916 \\
\hline HX-3-2/4 & 5.99 & 4.41 & 567.51 & 0.9916 \\
\hline HX-4 & 3.70 & 4.56 & 232.55 & 0.9969 \\
\hline HX-5-1/2 & 8.55 & 8.15 & 674.01 & 0.9844 \\
\hline HX-5-3/5 & 7.98 & 7.6 & 674.01 & 0.9829 \\
\hline HX-5-4/6 & 7.31 & 6.96 & 674.01 & 0.9836 \\
\hline HX-6-1/3 & 9.47 & 8.69 & 683.5 & 0.9824 \\
\hline HX-6-2/4 & 7.32 & 6.72 & 683.5 & 0.9820 \\
\hline HX-6-5/7 & 5.67 & 4.61 & 683.5 & 0.9808 \\
\hline HX-6-6/8 & 4.4 & 3.58 & 683.5 & 0.9805 \\
\hline
\end{tabular}

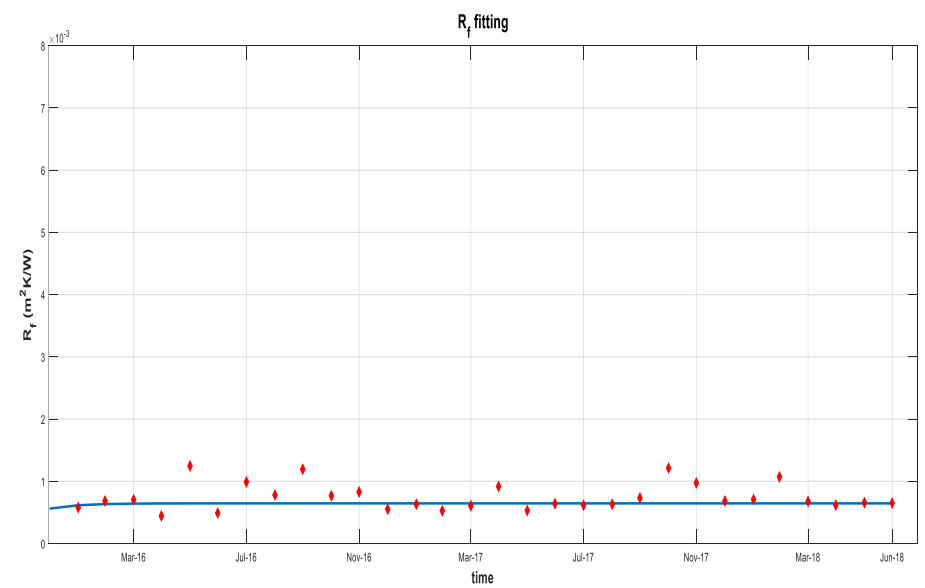

Fig. 4 Fouling resistance fitting.

Table 7 presents the asymptotic resistance values for each exchanger, the standard deviation of the supplied data, and the RMSE and R2 metrics. Values with RMSE equal to or close to the standard deviation and R2 greater than 0.5 were accepted. (Biyanto et al., 2016), make a similar adjustment of the fouling resistance to real data. However, they only consider R2. In the present work, the RMSE is included, pretending to have more significant selection criteria. Table 7 shows that the best RMSE obtained was equal to the standard deviation of the experimental data. In the case of R2, the best result was 0.99 , and the worst was 0.51 . All passed the criterion of being higher than 0.5 . The decay time was between 30 and 90 days, with 60 days being the most repeated or fashionable value of the data. Figure 4 shows the fouling data calculated with eq. 5 against the trend given by the Kern and Seaton correlation.

Using the models obtained for each exchanger, we proceed to carry out the other calculations necessary to find the heat flow and the effectiveness of each exchanger, namely, global heat transfer coefficient, logarithmic mean temperature difference, density, specific heat, and maximum heat flow. Already described in the methodology.

Table 7 Asymptotic resistance of each heat exchanger

\begin{tabular}{|l|l|l|l|l|l|}
\hline component & $R_{f}^{*}(\mathrm{~m} 2 \mathrm{~K} / \mathrm{W})$ & $\tau$ & $\sigma$ & $R M S E$ & $R 2$ \\
\hline HX-1-1/3 & 0.003160973 & 60 & $8.3 . \mathrm{E}-04$ & $8.6 . \mathrm{E}-04$ & 0.68 \\
\hline HX-1-2/4 & 0.005226491 & 90 & $1.0 . \mathrm{E}-03$ & $1.2 . \mathrm{E}-03$ & 0.65 \\
\hline HX-2-1/2 & 0.001495974 & 30 & $6.6 . \mathrm{E}-04$ & $6.6 . \mathrm{E}-04$ & 0.99 \\
\hline HX-3-1/3 & 0.001850270 & 30 & $4.8 . \mathrm{E}-03$ & $4.8 . \mathrm{E}-03$ & 0.96 \\
\hline HX-3-2/4 & 0.002131669 & 30 & $1.5 . \mathrm{E}-03$ & $1.5 . \mathrm{E}-03$ & 0.96 \\
\hline HX-4 & 0.002979546 & 30 & $4.5 . \mathrm{E}-04$ & $4.5 . \mathrm{E}-04$ & 0.93 \\
\hline HX-5-1/2 & 0.002371112 & 60 & $1.9 . \mathrm{E}-03$ & $2.0 . \mathrm{E}-03$ & 0.51 \\
\hline HX-5-3/5 & 0.004115219 & 60 & $1.7 . \mathrm{E}-03$ & $1.8 . \mathrm{E}-03$ & 0.89 \\
\hline HX-5-4/6 & 0.004098965 & 60 & $1.8 . \mathrm{E}-03$ & $1.9 . \mathrm{E}-03$ & 0.89 \\
\hline HX-6-1/3 & 0.004460026 & 60 & $1.6 . \mathrm{E}-03$ & $1.6 . \mathrm{E}-03$ & 0.67 \\
\hline HX-6-2/4 & 0.005893997 & 60 & $1.5 . \mathrm{E}-03$ & $1.6 . \mathrm{E}-03$ & 0.72 \\
\hline HX-6-5/7 & 0.008737302 & 60 & $1.4 . \mathrm{E}-03$ & $1.4 . \mathrm{E}-03$ & 0.85 \\
\hline HX-6-6/8 & 0.008140972 & 60 & $2.3 . \mathrm{E}-02$ & $2.3 . \mathrm{E}-02$ & 0.87 \\
\hline
\end{tabular}

Figure 5 shows the fouling trend of one of the exchangers under study. It can be seen that after the decay time $(\tau)$ has been reached, the fouling resistance value remains practically constant, although, in reality, the value oscillates near constant value. It happens because as the diameter decreases due to fouling, the speed increases.

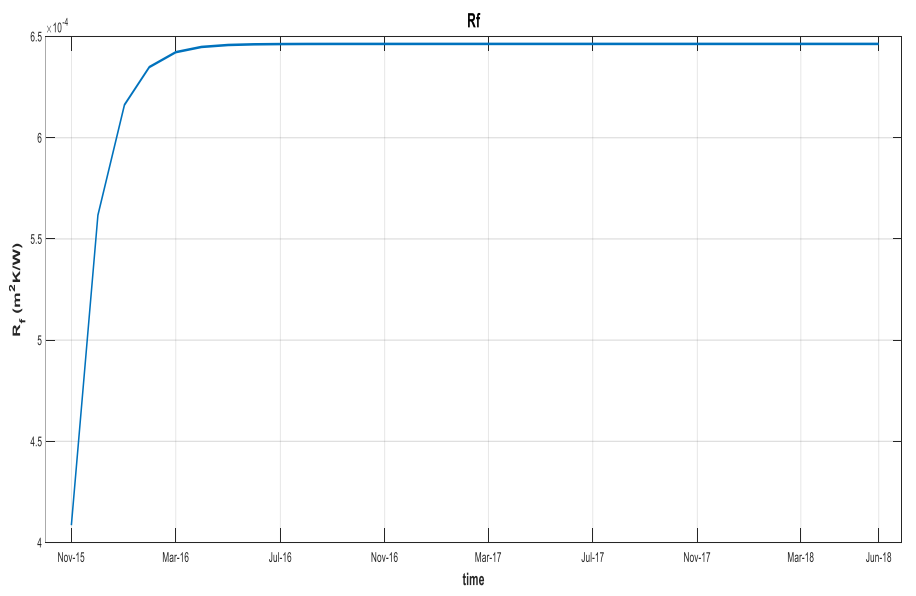

Fig. 5 Resistance trend provided by fouling. 
Said increase reaches such a point that it draws the fouling layers closest to the fluid (last layers formed) until the speed decreases due to the new diameter increase. The above is a repetitive process, and it makes it difficult to know the value of the fouling resistance exactly. It is called the asymptotic growth law or asymptotic hypothesis (Caputo et al., 2011; Zubair et al., 2000b).

Figure 6 shows the trend of the actual global heat transfer coefficient (red line). Here it can be seen as an inverse of the resistance due to fouling. However, in reality, it is a value that fluctuates, as it depends on many factors. Among them, the properties of the diet (a mixture of different crudes), which is modified according to market conditions. In turn, the design reference heat transfer coefficient (blue line) is shown. It is the value at which the customer expects the device to work.

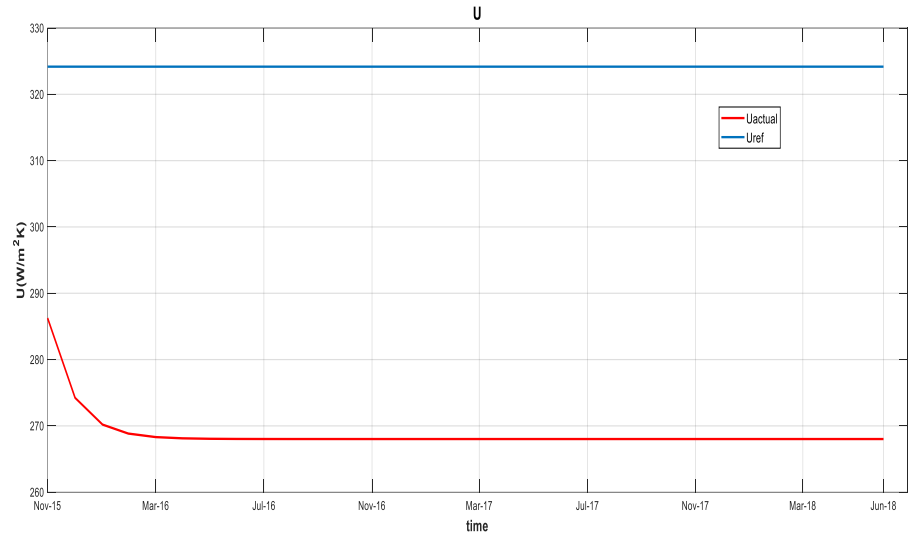

Fig. 6 Overall calculated current heat transfer coefficient trend.

Figure 7 shows the behavior of the actual heat flow (red line). For its calculation, the transfer area (supplied in the technical sheets of each equipment), the actual heat coefficient found above, and the corrected log-average temperature difference is taken into account, these are used in the equation 8 shown previously. The correction factors were taken from the equipment datasheets, and these are shown in Table 6. The orange line (figure 7) represents the reference heat flow given by the customer. The comparison between these two values at specific moments allows us to establish a difference between the performance expected by the client and the current one, and see how far they are from each other.

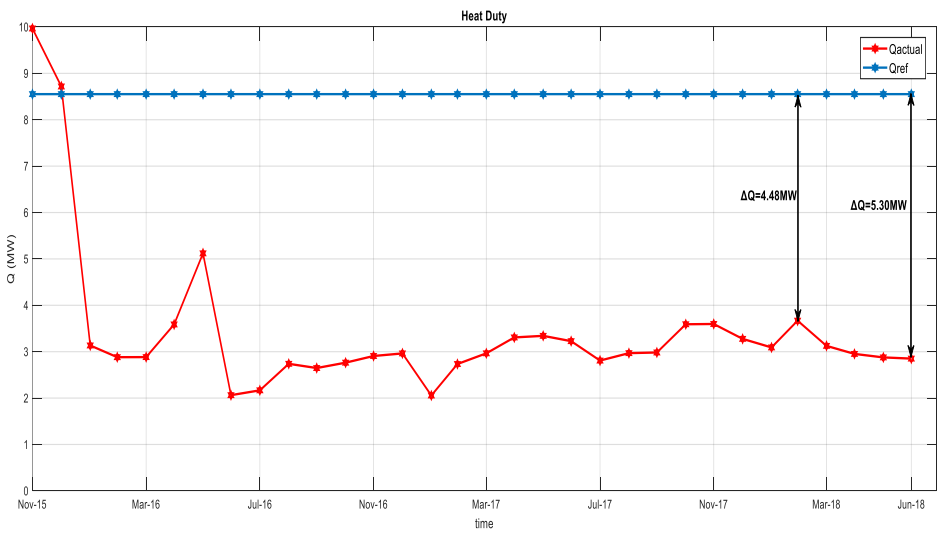

Fig. 7 Difference between reference heat and calculated actual heat.

Effectiveness was found with the ratio of actual heat flow to maximum flow (equation 12). According to (Yeap et al., 2004), this is the most convenient method for heat exchanger networks. The maximum heat flow shows the highest value, physically possible, with the supplied temperature and flow values for each moment. However, in the first months, effectiveness values greater than one are found, which is physically impossible unless the particular conditions in which the plant was operated are taken into account. The plant was designed for production of $993.77 \mathrm{~m} 3 / \mathrm{h}(150,000$ barrels of crude per day - BPD). The plant started with a flow close to $463.71 \mathrm{~m} 3 / \mathrm{h}$ (70,000 BPD), due to technical recommendations for plant stabilization and the learning stage. Production began in November 2015, and the flow was increased month by month until it reached values close (sometimes below, other times above) to $993.77 \mathrm{~m} 3 / \mathrm{h}(150,000 \mathrm{BPD})$.

The above caused the following situations: a) in some devices apparent effectiveness is shown to be much higher than one, in some cases more than two. It was because they were ultraclean equipment, with a large heat transfer area, and a crude flow rate of less than half (46.7\%) (see Fig. 8). For this reason, the effectiveness is observed very high in some heat exchangers in the first months. b) The resistance of experimental fouling very high in the first months. This because the equipment was operated at less than half of its operating capacity; this implied in the calculations a very low global heat transfer coefficient, and therefore a very high fouling resistance. c) Heat flow increasing over time. What is expected is that the transferred heat will decrease, but since the mass flow (which depends on the flow) was increasing month by month, this caused such an increase in the heat flow. It is pretty visible in some exchangers due to its location. However, knowing these implications, the methodology was tested to verify that, over time, the process adjusted to what was found in the literature, yielding excellent results (Fig. 9).



Fig. 8 Actual crude oil flow trend.

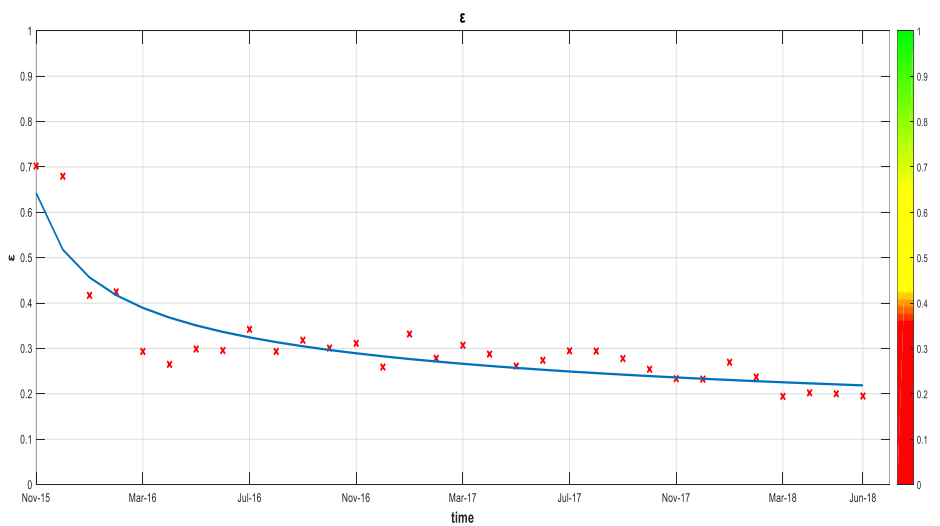

Fig. 9 Effectiveness trend of one exchanger.

For the heat flow data, all the models presented in Table 2 were used. The exponential models (Exp and Gauss) were the ones that best fit the data in general. The model used and the metrics for each exchanger are shown in Table 8. all the adjustments have an RMSE value less than the standard deviation of the data, which is a good indicator for the use of the prediction models. Also, it can be seen that the model that best fits the heat flow data was the Gauss. Table 9 presents the adjusted models for the heat exchanger. 
Table 8 Heat flow adjustment models and metrics for each heat exchanger

\begin{tabular}{|l|l|l|l|l|}
\hline TAG & Model & $\sigma$ & $R M S E$ & SSE \\
\hline HX-1-1/3 & Exp & 0.1798 & 0.1443 & 0.3955 \\
\hline HX-1-2/4 & Exp & 0.1892 & 0.1614 & 0.4947 \\
\hline HX-2-1/2 & Power1 & 0.6089 & 0.2851 & 0.2851 \\
\hline HX-3-1/3 & Gauss & 0.7898 & 0.2608 & 1.2920 \\
\hline HX-3-2/4 & Gauss & 0.7320 & 0.2142 & 1.0100 \\
\hline HX-4 & Gauss & 0.4218 & 0.1231 & 0.2879 \\
\hline HX-5-1/2 & Gauss & 1.3688 & 0.2760 & 1.6750 \\
\hline HX-5-3/5 & Gauss & 0.8854 & 0.1669 & 0.6131 \\
\hline HX-5-4/6 & Power2 & 1.2038 & 0.2059 & 0.9323 \\
\hline HX-6-1/3 & Exp & 0.8919 & 0.1969 & 0.7752 \\
\hline HX-6-2/4 & Gauss & 0.5957 & 0.2043 & 0.8763 \\
\hline HX-6-5/7 & Gauss & 0.8245 & 0.1512 & 0.3203 \\
\hline HX-6-6/8 & Gauss & 0.6465 & 0.1233 & 0.2281 \\
\hline
\end{tabular}

Table 9 Heat flow adjustment models for each heat exchanger

\begin{tabular}{|c|c|}
\hline Component & Adjustment models \\
\hline $\mathrm{HX}-1-1 / 3$ & $0.5379 e^{-0.01315 t}+2.859 e^{-0.00005030 t}$ \\
\hline $\mathrm{HX}-1-2 / 4$ & $106.4 e^{-0.02254 t}+2.414 e^{-0.00003751 t}$ \\
\hline $\mathrm{HX}-2-1 / 2$ & $12.25 t^{-0.129}$ \\
\hline $\mathrm{HX}-3-1 / 3$ & $\left(1.887 \times 10^{14}\right) e^{-\left(\frac{t+5206}{934.8}\right)^{2}}+1.463 e^{-\left(\frac{t-882.9}{839.1}\right)^{2}}$ \\
\hline $\mathrm{HX}-3-2 / 4$ & $\left(1.439 \times 10^{14}\right) e^{-\left(\frac{t+3554)}{641.8}\right)^{2}}+1.009 e^{-\left(\frac{t-766.9}{769.1}\right)^{2}}$ \\
\hline $\mathrm{HX}-4$ & $\left(8.891 \times 10^{13}\right) e^{-\left(\frac{t+2307}{418}\right)^{2}}+2.897 e^{-\left(\frac{t-1003}{2085}\right)^{2}}$ \\
\hline HX-5-1/2 & $\left(2.811 \times 10^{14}\right) e^{-\left(\frac{t+2300}{417.3}\right)^{2}}+3.242 e^{-\left(\frac{t-724}{864}\right)^{2}}$ \\
\hline $\mathrm{HX}-5-3 / 5$ & $\left(1.576 \times 10^{14}\right) e^{-\left(\frac{t+2056}{379.7}\right)^{2}}+2.314 e^{-\left(\frac{t-613.3)}{1124}\right)^{2}}$ \\
\hline $\mathrm{HX}-5-4 / 6$ & $100.2 t^{-0.8064}+1.558$ \\
\hline HX-6-1/3 & $6.980 e^{-0.01738 t}+2.649 e^{-0.00008521 t}$ \\
\hline HX-6-2/4 & $\left(1.426 \times 10^{14}\right) e^{-\left(\frac{t+1548}{287.6}\right)^{2}}+2.336 e^{-\left(\frac{t-689.6}{697.5}\right)^{2}}$ \\
\hline HX-6-5/7 & $\left(2.300 \times 10^{14}\right) e^{-\left(\frac{t+5012)}{894.2}\right)^{2}}+1.579 e^{-\left(\frac{t-932.4}{1439}\right)^{2}}$ \\
\hline HX-6-6/8 & $\left(2.290 \times 10^{1} 4\right) e^{-\left(\frac{t+5647}{1005}\right)^{2}}+1.359 e^{-\left(\frac{t-858.8)}{812.6}\right)^{2}}$ \\
\hline
\end{tabular}

The effectiveness data fits better with the power models. The model used and the metrics for each exchanger are shown in Table 10. The effectiveness adjustments also meet the criterion that the RMSE value is less than the deviation. The SSE value is closer to zero than in the heat flow settings for all cases. Table 10 also shows that the Power1 model was the best fit for the effectiveness data in most cases. The adjusted models for each equipment are shown in Table 11.
Table 10 Effectiveness adjustment models and metrics for each heat exchanger

\begin{tabular}{|l|l|l|l|l|}
\hline component & Model & $\sigma$ & $R M S E$ & SSE \\
\hline HX-1-1/3 & Power1 & 0.11365 & 0.05356 & 0.08608 \\
\hline HX-1-2/4 & Power1 & 0.12740 & 0.03529 & 0.03735 \\
\hline HX-2-1/2 & Gauss & 0.05928 & 0.04164 & 0.03641 \\
\hline HX-3-1/3 & Power2 & 0.17281 & 0.06057 & 0.10640 \\
\hline HX-3-2/4 & Exp & 0.15945 & 0.08683 & 0.21110 \\
\hline HX-4 & Exp & 0.11369 & 0.04010 & 0.04502 \\
\hline HX-5-1/2 & Exp & 0.12137 & 0.03745 & 0.02805 \\
\hline HX-5-3/5 & Power1 & 0.14787 & 0.02168 & 0.00846 \\
\hline HX-5-4/6 & Power1 & 0.09540 & 0.03922 & 0.03999 \\
\hline HX-6-1/3 & Exp & 0.10701 & 0.07033 & 0.12860 \\
\hline HX-6-2/4 & Exp & 0.12788 & 0.02652 & 0.01899 \\
\hline HX-6-5/7 & Power1 & 0.08855 & 0.05936 & 0.09867 \\
\hline HX-6-6/8 & Power1 & 0.08267 & 0.05536 & 0.08582 \\
\hline
\end{tabular}

Table 11 Effectiveness adjustment models for each heat exchanger

\begin{tabular}{|l|l|}
\hline component & Adjustment models \\
\hline HX-1-1/3 & $2.014 t^{-0.3066}$ \\
\hline HX-1-2/4 & $1.421 t^{-0.271}$ \\
\hline HX-2-1/2 & $\left(8.754 \times 10^{12}\right) e^{-\left(\frac{t+4757}{855.2}\right)^{2}}+0.4104 e^{-\left(\frac{t-775.3}{1521}\right)^{2}}$ \\
\hline HX-3-1/3 & $18.89 t^{-0.9069}+0.1894$ \\
\hline HX-3-2/4 & $1.863 e^{-0.02055 t}+0.2897 e^{-0.00009163 t}$ \\
\hline HX-4 & $0.7172 e^{-0.01855 t}+0.3401 e^{-0.00041940 t}$ \\
\hline HX-5-1/2 & $37.820 e^{-0.02955 t}+0.6160 e^{-0.00042800 t}$ \\
\hline HX-5-3/5 & $2.451 t^{-0.2992}$ \\
\hline HX-5-4/6 & $3.144 t^{-0.3404}$ \\
\hline HX-6-1/3 & $3.877 e^{-0.02677 t}+0.5246 e^{-0.00022470 t}$ \\
\hline HX-6-2/4 & $8.022 e^{-0.04152 t}+0.3378 e^{-0.00019710 t}$ \\
\hline HX-6-5/7 & $1.834 t^{-0.2633}$ \\
\hline HX-6-6/8 & $1.687 t^{-0.2431}$ \\
\hline
\end{tabular}

Table 12 presents the maintenance assumptions, and Figure 10 presents the logic of maintenance planning. It leads to timely and justified planning of cleaning the heat exchangers.

Table 12 Maintenance assumptions

\begin{tabular}{|l|l|}
\hline$N^{\circ}$ & maintenance assumptions \\
\hline 1 & $\begin{array}{l}\text { without affecting the strategies derived from the maintenance } \\
\text { schedules based on reliability and risk. Maintenance activities } \\
\text { will only be scheduled on exchangers with a value of J above } \\
\text { the threshold. (Table 3). }\end{array}$ \\
\hline 2 & $\begin{array}{l}\text { Enlistment and execution of maintenance activities must be } \\
\text { carried out in less than a calendar month }\end{array}$ \\
\hline 3 & $\begin{array}{l}\text { If maintenance activities affect adjacent equipment, for } \\
\text { example in disassembly needs, efforts will be made to carry } \\
\text { out simultaneous maintenance on the affected equipment, for } \\
\text { better use of resources and avoiding lost profits. }\end{array}$ \\
\hline 4 & $\begin{array}{l}\text { If two types of maintenance are justified, the one that brings } \\
\text { the heat exchanger closer to its design conditions will be } \\
\text { selected whenever the operation allows it. }\end{array}$ \\
\hline 5 & $\begin{array}{l}\text { Similar and spatially close heat exchangers will be carried out } \\
\text { maintenance activities simultaneously. }\end{array}$ \\
\hline 6 & $\begin{array}{l}\text { After carrying out maintenance on one of these groups of } \\
\text { exchangers, there will be time for stabilization of the process } \\
\text { and economic recovery. }\end{array}$ \\
\hline
\end{tabular}






Heat exchangers with the lowest effectiveness (less than 45\%) and that also have justification for any of the types of maintenance will be programmed first. The approach of this methodology is firmly based on the profit margin of the business. The operating conditions, market requirements, and profit margin prevail over other activities; this is how it happens in most refineries around the world. A year was divided into four parts (quarters, table 13 summarizes this), and the last month of each quarter was chosen to predict the indicators and plan maintenance activities. Within these quarters, the planned maintenance will be carried out. Considering the previous, table 14 show the prognosis made between May and July in 2018 for the effectiveness and $\mathrm{J}$ in some heat exchangers.

Table 13 Year in quarters

\begin{tabular}{|l|l|}
\hline Months & Quarter \\
\hline January to March & I \\
\hline April to June & II \\
\hline July to September & III \\
\hline October to December & IV \\
\hline
\end{tabular}

Fig. 10 Flow diagram maintenance planning

Table 14 Effectiveness and $\mathrm{J}$ prognosis in some heat exchangers

\begin{tabular}{|c|c|c|c|c|c|c|c|c|c|c|c|c|c|c|c|c|c|c|c|c|}
\hline \multirow[b]{2}{*}{$H E$} & \multicolumn{4}{|c|}{ IV Q-2018 } & \multicolumn{4}{|c|}{$I Q-2019$} & \multicolumn{4}{|c|}{ II Q -2019 } & \multicolumn{4}{|c|}{ III Q-2019 } & \multicolumn{4}{|c|}{ IV Q-2019 } \\
\hline & $\varepsilon$ & $J \_A$ & $J_{-} B$ & $J_{-} C$ & $\varepsilon$ & $J \_A$ & $J \_B$ & $J_{-} C$ & $\varepsilon$ & $J \_A$ & $J \_B$ & $J_{-} C$ & $\varepsilon$ & $J \_A$ & $J \_B$ & $J_{-} C$ & $\varepsilon$ & $J \_A$ & $J \_B$ & $J_{-} C$ \\
\hline HX-4 & 0.21 & 1.11 & 2.43 & 6.09 & 0.20 & 1.12 & 2.47 & 6.17 & 0.19 & 1.14 & 2.52 & 6.30 & 0.19 & 1.17 & 2.58 & 6.46 & 0.18 & 1.21 & 2.66 & 6.66 \\
\hline $\mathrm{HX}-5-1 / 2$ & 0.38 & 1.28 & 2.81 & 7.02 & 0.36 & 1.34 & 2.95 & 7.36 & 0.35 & 1.40 & 3.09 & 7.73 & 0.33 & 1.47 & 3.24 & 8.09 & 0.32 & 1.54 & 3.38 & 8.44 \\
\hline HX-5-3/5 & 0.30 & 1.31 & 2.88 & 7.20 & 0.29 & 1.34 & 2.95 & 7.38 & 0.28 & 1.38 & 3.03 & 7.58 & 0.28 & 1.41 & 3.11 & 7.78 & 0.27 & 1.45 & 3.19 & 7.98 \\
\hline HX-5-4/6 & 0.28 & 1.15 & 2.53 & 6.32 & 0.28 & 1.15 & 2.54 & 6.35 & 0.27 & 1.16 & 2.55 & 6.37 & 0.27 & 1.16 & 2.56 & 6.39 & 0.26 & 1.16 & 2.56 & 6.41 \\
\hline HX-6-1/3 & 0.40 & 1.41 & 3.10 & 7.74 & 0.40 & 1.41 & 3.11 & 7.76 & 0.39 & 1.42 & 3.11 & 7.79 & 0.38 & 1.42 & 3.12 & 7.81 & 0.37 & 1.42 & 3.13 & 7.83 \\
\hline HX-6-2/4 & 0.27 & 1.17 & 2.57 & 6.43 & 0.26 & 1.23 & 2.70 & 6.75 & 0.26 & 1.28 & 2.82 & 7.06 & 0.25 & 1.33 & 2.93 & 7.34 & 0.25 & 1.38 & 3.03 & 7.58 \\
\hline HX-6-5/7 & 0.29 & 0.69 & 1.51 & 3.78 & 0.28 & 0.69 & 1.53 & 3.82 & 0.28 & 0.71 & 1.55 & 3.88 & 0.27 & 0.72 & 1.58 & 3.95 & 0.27 & 0.73 & 1.61 & 4.03 \\
\hline HX-6-6/8 & 0.30 & 0.53 & 1.18 & 2.94 & 0.30 & 0.56 & 1.23 & 3.07 & 0.29 & 0.59 & 1.29 & 3.22 & 0.29 & 0.62 & 1.35 & 3.38 & 0.28 & 0.64 & 1.42 & 3.54 \\
\hline
\end{tabular}

The intervention of heat exchangers shown in table 13 was easily justified before the business management, who was concerned about the relationship of maintenance costs and the profit margin of the business, given a downward oil price scenario. The proposed maintenance indicator "J" has economic significance, which makes it understandable to managers.

Taking into account all of the above, namely: a) maintenance assumptions (table 11), b) logical order to plan maintenance (fig. 10), c) distribute the year in quarters (Table 13), and d) effectiveness and indicator J prognosis (table 14, maintenance planning was carried out for some devices of the exchanger network under study. Figure 11 shows a summary of the criticality matrix of the interventions, and table 15, shows a summary of the schedule of cleaning interventions.

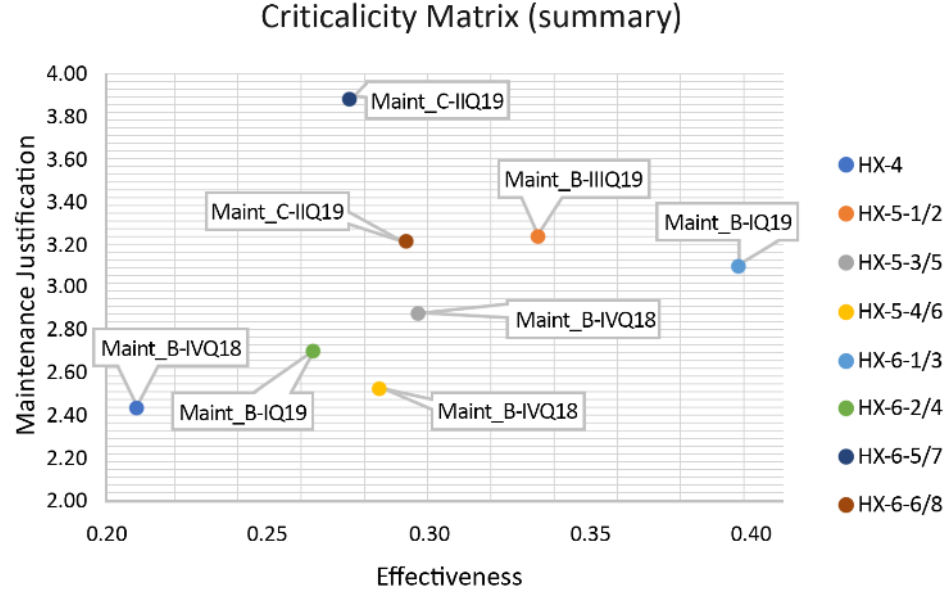

Fig. 11 Summary of the criticality matrix 
Table 15 Maintenance Schedule

\begin{tabular}{|l|l|l|l|l|}
\hline Year & 2018 & \multicolumn{3}{l|}{2019} \\
\hline HElQuarter & IV $Q$ & I $Q$ & II $Q$ & III $Q$ \\
\hline HX-4 & B & & & \\
\hline HX-5-1/2 & & & & B \\
\hline HX-5-3/5 & B & & & \\
\hline HX-5-4/6 & B & & & \\
\hline HX-6-1/3 & & B & & \\
\hline HX-6-2/4 & & B & & \\
\hline HX-6-5/7 & & & C & \\
\hline HX-6-6/8 & & & C & \\
\hline
\end{tabular}

It is possible to observe from table 13 and figure 11, that the teams' effectiveness forecast is less than $45 \%$. On the other hand, maintenance A (see tables 3 and 4) is not justified by indicator $J$ in any of the equipment. Premises 3 and 5 in table 11 were taken into account for the planning of the interventions in the HX-4 exchanger, together with the HX 5-3, HX 5-4, HX 5-5, and HX 5-6 exchangers. The same was right for planning on HX 6-1, HX 6-2, HX 6-3, and HX 6-4 devices in the first quarter of 2019, HX 6-5, HX 6-6, HX 6-7 and HX 6-8 devices in the second quarter of 2019, and the HX 5-1 and HX 5-2 devices in the third quarter of 2019. Figure 12 shows a zoom of the teams with their tags for better identification.

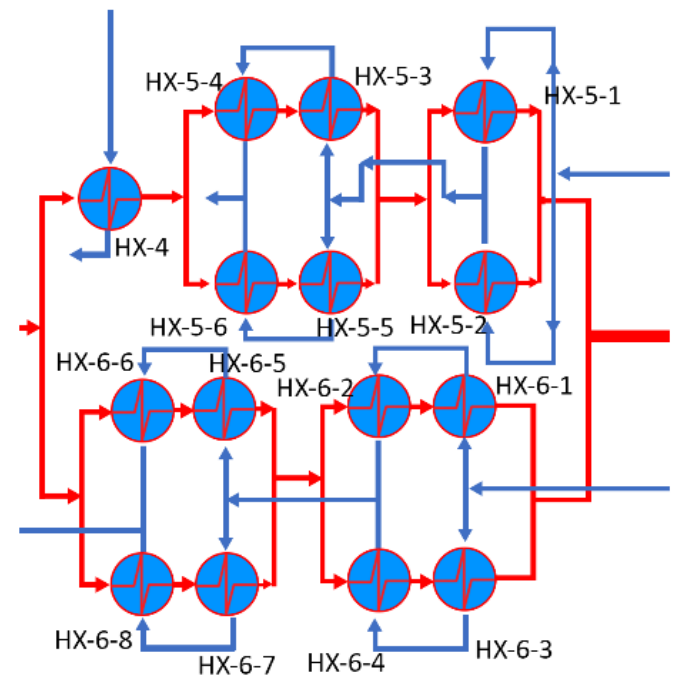

Fig. 12 Tags of heat exchangers

The application of this methodology in some devices of the preheating train of a unit of crude oil allowed savings of up to USD 150,000 to be achieved. For reasons of confidentiality of the company that applied the results, specific information used in the planning of maintenance interventions are not disclosed.

\section{CONCLUSIONS}

This article presented the efficiency-focused maintenance strategy based on the literature and with the available resources. The strategy does not consider physical modifications in the devices or in the process - it seeks to modify the planning of cleaning interventions. It was found that it is possible to plan cleaning interventions in heat exchanger networks, which are economically sustainable, without carrying out costly computer simulations. These interventions were based on the thermal efficiency of the heat exchangers and an indicator called $\mathrm{J}$ by the authors.
This indicator relates the economic-energy improvement achieved with the performance of maintenance interventions and the economic effort invested in carrying out said maintenance on the asset. Assumptions and logic were made to plan the activities to be carried out. Models were developed from historical data to forecast the efficiency and heat flow of the equipment under study. Finally, the methodology was applied to some of the heat exchangers in the network. This methodology was implemented and allowed to achieve savings of up to USD 150,000. The intervention of heat exchangers under the proposed approach is easily justifiable because the proposed maintenance indicator is economically important for business management.

Several authors have made the cleaning schedule for the heat exchanger network equipment based on simulations, non-linear programming, among other optimization strategies. This work was carried out through indicators and simple prediction models. The proposed methodology can also be applied to evaluate the economic impact of maintenance interventions carried out in the past. The conceptual design of the proposed methodology can be implemented in other types of heat exchangers, and other energy transformation equipment (such as turbines or compressors), making the necessary adjustments due to the type of process in which each equipment is immersed. It is also possible to implement it in industries other than the oil and gas sector.

\section{ACKNOWLEDGEMENTS}

The authors gratefully thank to the Universidad Tecnológica de Bolívar (UTB) for facilitating this research and the MSc Orlando Viloria Marimon for the suggestions during the preparation of this paper.

\section{NOMENCLATURE}

\begin{tabular}{|c|c|}
\hline$A$ & Heat transfer area $(\mathrm{m} 2)$ \\
\hline$\dot{m}$ & mass flux $(\mathrm{Kg} / \mathrm{s})$ \\
\hline$T$ & Temperature $\left({ }^{\circ} \mathrm{C}\right)$ \\
\hline$Q$ & Heat transferred (KW) \\
\hline$\dot{Q}$ & Heat flux or Heat duty (K.W.) \\
\hline$C$ & Cost (\$ USD) \\
\hline$C_{p}$ & specific heat $(\mathrm{J} / \mathrm{kgK})$ \\
\hline $\begin{array}{l}C M L D \\
\left({ }^{\circ} \mathrm{C}\right)\end{array}$ & Corrected Logarithmic Mean Temperature Difference \\
\hline$L M D T$ & Logarithmic mean temperature difference $\left({ }^{\circ} \mathrm{C}\right)$ \\
\hline$f$ & Correction factor for the logarithmic mean temperature \\
\hline$U$ & overall heat transfer coefficient $((\mathrm{W} / \mathrm{m} 2 \mathrm{~K})$ \\
\hline$R$ & Thermal Resistance $\left(\mathrm{m}^{2} \mathrm{~K} / \mathrm{W}\right)$ \\
\hline$t$ & time (day) \\
\hline$K P P$ & Key Performance Parameter \\
\hline$C A M$ & Cost Assessment Matrix \\
\hline$R A M$ & Risk Assessment Matrix \\
\hline \multicolumn{2}{|c|}{ Greek Symbols } \\
\hline & Energy efficiency \\
\hline & Density (Kg/m3) \\
\hline & Difference \\
\hline & Decay time \\
\hline
\end{tabular}

\section{Superscripts}

* Asymptotic case

Subscripts

$d \quad$ Design value

ref Reference value (expected by the customer)

$\exp \quad$ Actual value

$f \quad$ Fouling condition 


$\begin{array}{ll}\text { lm } & \text { Logarithmic mean } \\ c & \text { Cold } \\ h & \text { Hot } \\ i & \text { Inlet } \\ o & \text { Outlet } \\ \text { max } & \text { Maximum possible value } \\ \text { maint } & \text { Maintenance } \\ l p & \text { Lost profit } \\ e & \text { Energy } \\ o p & \text { Opportunity }\end{array}$

\section{REFERENCES}

Assis, B. C. G., Gonçalves, C. de O., Liporace, F. S., Oliveira, S. G., Queiroz, E. M., Pessoa, F. L. P., and Costa, A. L. H., 2013, "Constrained thermohydraulic optimization of the flow rate distribution in crude preheat trains," Chemical Engineering Research and Design, 91(8), 1517-1526.

https://doi.org/10.1016/j.cherd.2013.06.005

Ba, Q., Egbert, S., Li, X., \& Cheng, L.,2019, "Measurements and modeling of fluid flow and thermal processes in an industrial precalciner," Frontiers in Heat and Mass Transfer, 12(20), 1-8 https://doi.org/10.5098/hmt.12.20

Bennett, C. A., 2012, "A theory describing asphaltene adhesion fouling inside heat exchanger tubes," Heat Transfer Engineering, 33(15), 1246-1250.

https://doi.org/10.1080/01457632.2012.692295

Biyanto, T. R., Ramasamy, M., Jameran, A. B., and Fibrianto, H. Y., 2016, "Thermal and hydraulic impacts consideration in refinery crude preheat train cleaning scheduling using recent stochastic optimization methods," Applied Thermal Engineering, 108, 14361450.

https://doi.org/10.1016/j.applthermaleng.2016.05.068

Boonloi, A., \& Jedsadaratanachai, W., 2019, "Thermal performance improvement in a square channel heat exchanger with various parameters of v-wavy plates," Frontiers in Heat and Mass Transfer, 12(1), 1-9.

https://doi.org/10.5098/hmt.12.1

Borges, J. L., Queiroz, E. M., Pessoa, F. L. P., Liporace, F. S., Oliveira, S. G., and Costa, A. L. H., 2009, "Fouling management in crude oil preheat trains through stream split optimization," Computer Aided Chemical Engineering, 27(C), 1587-1592.

https://doi.org/10.1016/S1570-7946(09)70655-8

Bott, T. R., 1995, Fouling of heat exchangers, vol. 26, Elsevier Science B.V., Birmingham, UK.

Caputo, A. C., Pelagagge, P. M., and Salini, P., 2011, "Joint economic optimization of heat exchanger design and maintenance policy," Applied Thermal Engineering, 31(8-9), 1381-1392.

https://doi.org/10.1016/j.applthermaleng.2010.12.033

Cengel, Y. A., 2003, Heat Transfer a practical Approach, $2^{\text {nd }}$ Ed, McGraw-Hill Education, New York, NY.
Coletti, F, 2010, Multi-scale Modelling of Refinery Pre-heat Trains Undergoing Fouling for Improved Energy Efficiency, Phd Tesis, Imperial College London.

Coletti, F., and Macchietto, S., 2009, "Predicting refinery energy losses due to fouling in heat exchangers," Computer Aided Chemical Engineering, 27(C), 219-224.

https://doi.org/10.1016/S1570-7946(09)70257-3

de Oliveira Filho, L. O., Liporace, F. S., Queiroz, E. M., and Costa, A. L. H., 2009, "Investigation of an alternative operating procedure for fouling management in refinery crude preheat trains," Applied Thermal Engineering, 29(14-15), 3073-3080.

https://doi.org/10.1016/j.applthermaleng.2009.04.012

Georgiadis, M. C., and Papageorgiou, L. G., 2000, "Optimal energy and cleaning management in heat exchanger networks under fouling," Chemical Engineering Research and Design, 78(2), 168179.

https://doi.org/10.1205/026387600527194

Georgiadis, Michael C, Papageorgiou, L. G., and Macchietto, S., 2000, "Optimal Cleaning Policies in Heat Exchanger Networks under Rapid Fouling," Industrial and Engineering Chemistry Research, 39(2), 441-454.

https://doi.org/10.1021/ie990166c

Incropera, F. P., Bergman, T. L., Lavine, A. S., and Dewitt, D. P., 2011, Fundamentals of heat and mass transfer, $7^{\text {th }}$ ed., John Wiley \& Sons, Hoboken, NJ.

Ishiyama, E. M., Heins, A. V, Paterson, W. R., Spinelli, L., and Wilson, D. I., 2010, "Scheduling cleaning in a crude oil preheat train subject to fouling: Incorporating desalter control," Applied Thermal Engineering, 30(13), 1852-1862.

https://doi.org/10.1016/j.applthermaleng.2010.04.027

Ishiyama, E. M., Paterson, W. R., and Wilson, D. I., 2008, "Thermohydraulic channelling in parallel heat exchangers subject to fouling," Chemical Engineering Science, 63(13), 3400-3410. https://doi.org/10.1016/j.ces.2008.04.008

Izyan, Z. N., Noryani, M., Dayanasari, A. H., and Shuhaimi, M., 2014, "MINLP model for simultaneous scheduling and retrofit of refinery preheat train," International Journal of Energy and Environment, 5(2), 197-206. www.IJEE.IEEFoundation.org

Kaminski, Deborah., and Jensen, M. K., 2005, Introduction to thermal and fluids engineering, John Wiley \& Sons, Hoboken, NJ.

Kern, D. Q., 1983, Process heat transfer, International student edition, McGraw-Hill Book Company, Tokyo, JP.

Kern, D., and Seaton, R., 1959, "A theoretical analysis of thermal surface fouling," Br. Chem. Eng., 4, 258-262.

Kuppan, T., 2013, Heat exchanger design handbook, $2^{\text {nd }}$ ed., CRC Press, Taylor \& Francis Group, Boca Raton, FL. 
Ludwig, E. E., 1997, Applied process design for chemical and petrochemical plants, vol. 2, $3^{\text {rd }}$ ed., Gulf Professional Publishing, Houston, TX.

Polley, G. T., Wilson, D. I., Yeap, B. L., and Pugh, S. J., 2002, "Evaluation of laboratory crude oil threshold fouling data for application to refinery pre-heat trains," Applied Thermal Engineering, 22(7), 777-788.

https://doi.org/10.1016/S1359-4311(02)00023-6

Rodriguez, C., and Smith, R., 2007, "Optimization of operating conditions for mitigating fouling in heat exchanger networks," Chemical Engineering Research and Design, 85(6 A), 839-851.

https://doi.org/10.1205/cherd06046

Sanaye, S., and Niroomand, B., 2007, "Simulation of heat exchanger network (HEN) and planning the optimum cleaning schedule," Energy Conversion and Management, 48(5), 1450-1461.

https://doi.org/10.1016/j.enconman.2006.12.006

Schlunder, E. U., 1983, Heat exchanger design handbook, Hemisphere Publishing, New York, NY.

Shah, R. K., and Sekulić, D. P., 2003, Fundamentals of heat exchanger design. John Wiley \& Sons, Hoboken, NJ.

https://doi.org/10.1002/9780470172605

Smaïli, F., Vassiliadis, V. S., and Wilson, D. I., 2001, "Mitigation of Fouling in Refinery Heat Exchanger Networks by Optimal Management of Cleaning," Energy and Fuels, 15(5), 1038-1056. https://doi.org/10.1021/ef010052p

Tajudin, Z. Bin., 2015, Experiments, Modelling and Validation of Crude Oil Fouling on Large Scale Rig Phd Tesis, Imperial College London.

Tian, J., Wang, Y., and Feng, X., 2016, "Simultaneous optimization of flow velocity and cleaning schedule for mitigating fouling in refinery heat exchanger networks," Energy, 109, 1118-1129. https://doi.org/10.1016/j.energy.2016.05.053

Tubular Exchanger Manufacturers Association, Inc., 2007, Standards of the tubular exchanger manufacturers association, $9^{\text {th }}$ ed., Tubular Exchanger Manufacturers Association, Inc., Tarrytown, NY.

Wang, F.-L., He, Y.-L., Tong, Z.-X., and Tang, S.-Z., 2017, "Realtime fouling characteristics of a typical heat exchanger used in the waste heat recovery systems," International Journal of Heat and Mass Transfer, 104, 774-786.

https://doi.org/10.1016/j.ijheatmasstransfer.2016.08.112

Waters, A. J., Akinradewo, C. G., and Lamb, D, 2009, "Fouling: Implementation of a Crude Preheat Train Performance Monitoring Application at the Irving Oil Refinery," International Conference on Heat Exchanger Fouling and Cleaning VIII, 33-38.

Watkinson, A., 2003, "Comparison of Crude Oil Fouling Using Two Different Probes," Heat Exchanger Fouling and Cleaning: Fundamentals and Applications, 234-241.

Yeap, B. L., Wilson, D. I., Polley, G. T., and Pugh, S. J., 2004, "Mitigation of crude oil refinery heat exchanger," Chemical Engineering, 82(January), 53-71. https://doi.org/10.1205/026387604772803070

Zubair, S. M., Sheikh, A. K., Younas, M., and Budair, M. O., 2000, "A risk based heat exchanger analysis subject to fouling Part I: Performance evaluation," Energy, 25(5), 427-443. https://doi.org/10.1016/S0360-5442(99)00080-8

Zubair, S. M., Sheikh, A. K., Younas, M., and Budair, M. O., 2000, "A risk based heat exchanger analysis subject to fouling Part II: Economics of heat exchangers cleaning," Energy, 25(5), 445-461. https://doi.org/10.1016/S0360-5442(99)00081-X 